\title{
SEISMIC ISOLATION OF BRIDGES IN ITALY
}

\author{
Albert Parducci ${ }^{1}$ and Marco Mezzi ${ }^{1}$ \\ This paper was presented at the \\ Pacific Conference on Earthquake Engineering \\ New Zealand, November 1991.
}

\begin{abstract}
SUMMARY
A great number of Italian highway bridges have been provided with seismic isolating devices. As a typical example of the criteria for the design of such structures the bridges of a new highway are illustrated. They are composed of various continuous multi-span sections. The seismic isolating systems have been designed on the basis of the dissipating behaviour of elastic-plastic restrainers. With reference to the cases studied, general considerations concerning the design of optimum structural configuration suggested by the use of seismic isolation, are also discussed.
\end{abstract}

\section{ITALIAN EXPERIENCE IN SEISMIC ISOLATION}

In recent years great experience in seismic isolation has been developed in Italy concerning both theoretical and experimental research, and the construction of significant works. Some important buildings for public housing have been built providing them with base isolating systems. But the wider use of seismic isolation has been made in the field of bridge construction $[1,7,9]$. At present, about one hundred bridge structures located in seismic areas have been provided with isolating devices of different types and different effectiveness, while the building of an equal number of isolated bridges has been planned.

The isolated bridges are located in the following sections of the Italian highway network of "Autostrade", "SAT" and "ANAS" Companies (Fig.1):

-New constructions:
-A Udine-Carnia
-B E.45 (Perugia-Cesena)
32 bridges (1976-1984)
-C Raccordo autostradale (Roma)
5 bridges $(1985-1990)$
-D Vittorio Veneto-Pian di Vedoia
-E Livorno-Civitavecchia
22 bridges (1985-1988)
-F Variante appenninica
9 bridges $(1989-->)$
5 bridges $(1989->)$
( $\approx 30$ bridges) (to be designed)

-Retrofitted structures:

-G Napoli - Bari

-H Firenze-Bologna

-H Roma-Napoli

-J Salerno-Reggio Calabria

\author{
22 bridges (1984-1991) \\ 2 bridges (1988-1990) \\ 12 bridges (1988-1991)
}

( $\approx 50$ bridges) (to be designed)

In order to give an idea of the economic commitment of the planned works, the estimated data shown in the following tables, concerning both new (Tables 1 and 2) and retrofitted bridges (Table 3), are presented.

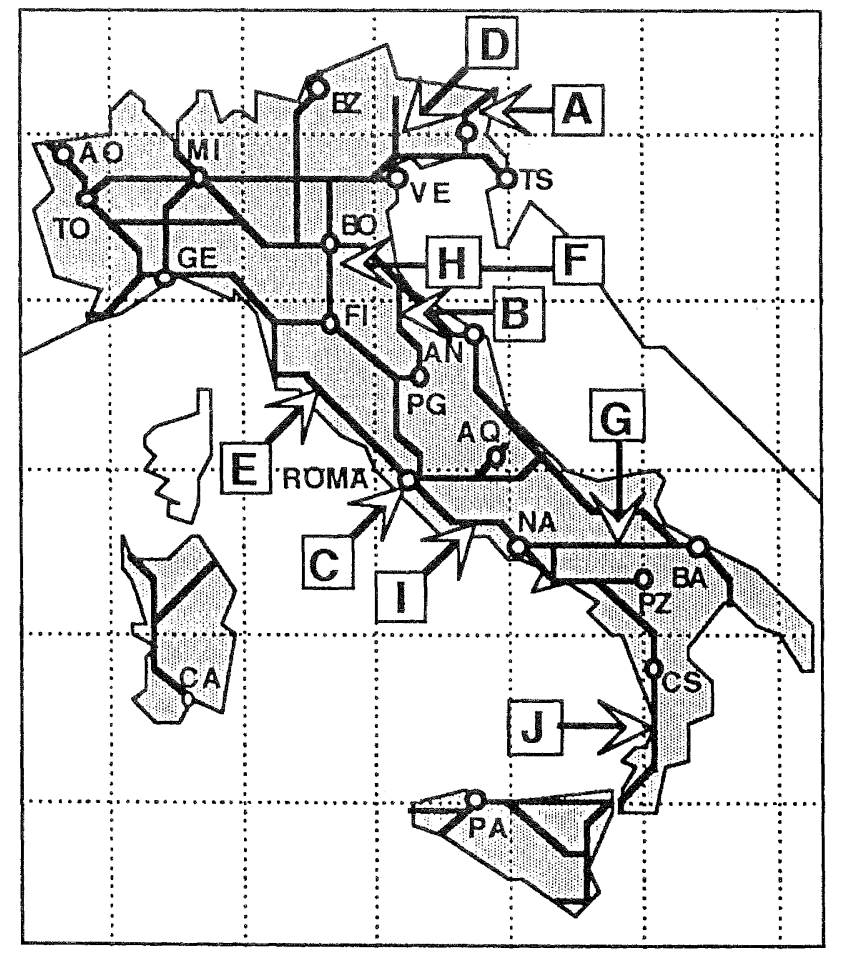

Fig.1 General Layout of the Italian highway network.

${ }^{1}$ Faculty of Engineering, University of Perugia, Italy. 


\begin{tabular}{|c|c|c|c|c|c|}
\hline Bridges & $\begin{array}{l}\text { total length } \\
\text { (m) }\end{array}$ & $\begin{array}{c}\text { structure } \\
\text { (US\$/1000) }\end{array}$ & $\begin{array}{c}\text { supports } \\
\text { (US\$/1000) }\end{array}$ & $\begin{array}{c}\text { isolation } \\
\text { (US } \$ / 1000)\end{array}$ & $\begin{array}{l}\text { isolating } \\
\text { scheme }(\cdot)\end{array}$ \\
\hline $\begin{array}{l}\text { Mortaiolo } \\
\text { Morra } \\
\text { Savalano } \\
\text { (Poggio lb.) } \\
\text { Gonnellion }\end{array}$ & $\begin{array}{r}9,600 \\
900 \\
1,900 \\
(2,500) \\
700\end{array}$ & $\begin{array}{c}180,000 \\
11,000 \\
22,000 \\
(33,000) \\
10,000\end{array}$ & $\begin{array}{r}5,600 \\
500 \\
1,300 \\
(1,400) \\
700\end{array}$ & $\begin{array}{c}8,400 \\
200 \\
270 \\
(1960) \\
130\end{array}$ & $\begin{array}{rr}\text { C } & \text { (bi-direct.) } \\
\text { A } & \text { (only long.) } \\
\text { A } & \text { (only long.) } \\
\text { (non-dissip.) } \\
\text { A (only long.) }\end{array}$ \\
\hline Total & 13,100 & 223,000 & 8,100 & 9,000 & \\
\hline
\end{tabular}

$(\cdot)$ Isolating schemes are described below

\section{TABLE 2}

Estimated data for new bridges

\begin{tabular}{||l|c|c|c|c|c||}
\hline Highway section & $\begin{array}{c}\text { total length } \\
(\mathbf{m})\end{array}$ & $\begin{array}{c}\text { structures } \\
\text { (US\$/1000) }\end{array}$ & $\begin{array}{c}\text { supports } \\
(\mathbf{U S} \mathbf{\$ 1 0 0 0})\end{array}$ & $\begin{array}{c}\text { isolation } \\
(\mathbf{U S} \mathbf{\$ 1 0 0 0})\end{array}$ & $\begin{array}{c}\text { isolating } \\
\text { scheme }\end{array}$ \\
\hline Racc.autostr. [C] & 6,500 & 120,000 & 1,800 & 2,500 & (long) \\
V.Ven.-P.di Ved [D] & 3,300 & 64,000 & 2,300 & 5,200 & (bi-direct) \\
Livorno-Civitav. [E] & 13,100 & 223,000 & 8,100 & 9,000 & (var.) \\
\hline Total amounts & 22,900 & 407,000 & 12,200 & 16,700 & \\
\hline
\end{tabular}

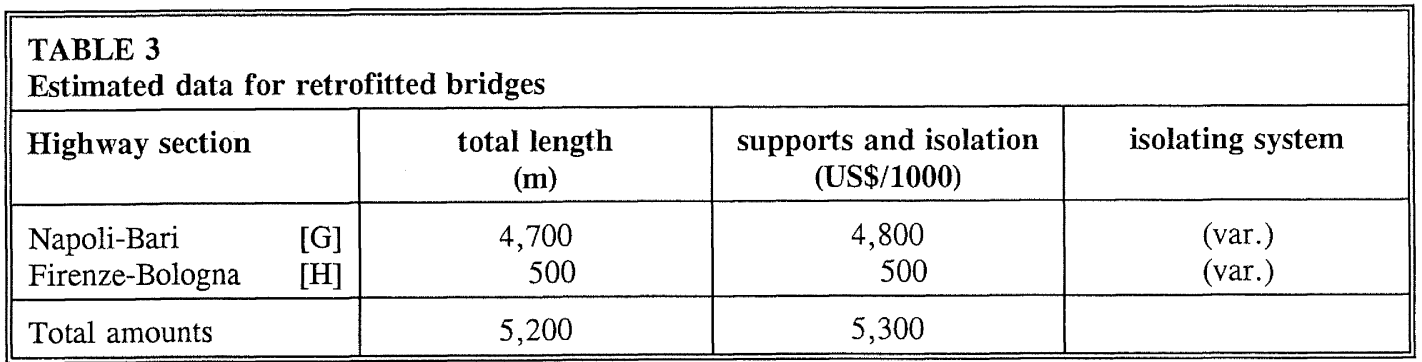

Different criteria have been assumed by the designer in order to isolate the deck structures of all these bridges [2]. In the present paper the isolating design of the bridges, which are being built in the section Livorno-Cecina of the highway Livorno-Civitavecchia (E-section in Fig.1) are described in order to illustrate some typical examples of the most recent criteria with which isolated bridge structures are designed in Italy, taking into account the actual building procedures of modern bridge construction. Particularly, the Mortaiolo Bridge is examinated and its full isolating system, which has been designed by the authors of the paper, together with the design procedures, the functioning of the mechanical devices, their experimental tests and some economic estimations, are described in detail. Finally, brief consideration is also developed about some particular criteria assumed in the retrofitting of existent bridges.

\section{SEISMIC ISOLATION AND BUILDING PROCEDURES}

The bridges of the E-section are located in seismic zones where the attack of strong earthquakes is expected. Therefore, non- conventional seismic protection of the structures have been foreseen and seismic isolation systems have been designed. The goals of the design were to reduce seismic accelerations transmitted to the masses of the superstructure during the attacks of the major expected earthquakes and thus improve the seismic protection of the supporting structures (piers and foundations).

Concerning the development of building procedures, continuous multi-span girders have become the usual scheme for bridge structures. Generally, they are built by means of a progressive procedure (Fig.2); otherwise, single-spans girders built with precast beams are connected in the longitudinal direction by means of continuous slab or deck elements (Fig.3). Often, the continuous slab systems have been utilized when existing bridges, built 20 or 30 years ago with single-span beams, have been retrofitted; so, the frequent troubles deriving from faults in the paving-joints can also be eliminated, improving the durability of the structure. In any case, the general isolating criterion is based on the separation of the superstructure from the piers by means of dissipating elastic-plastic devices. 


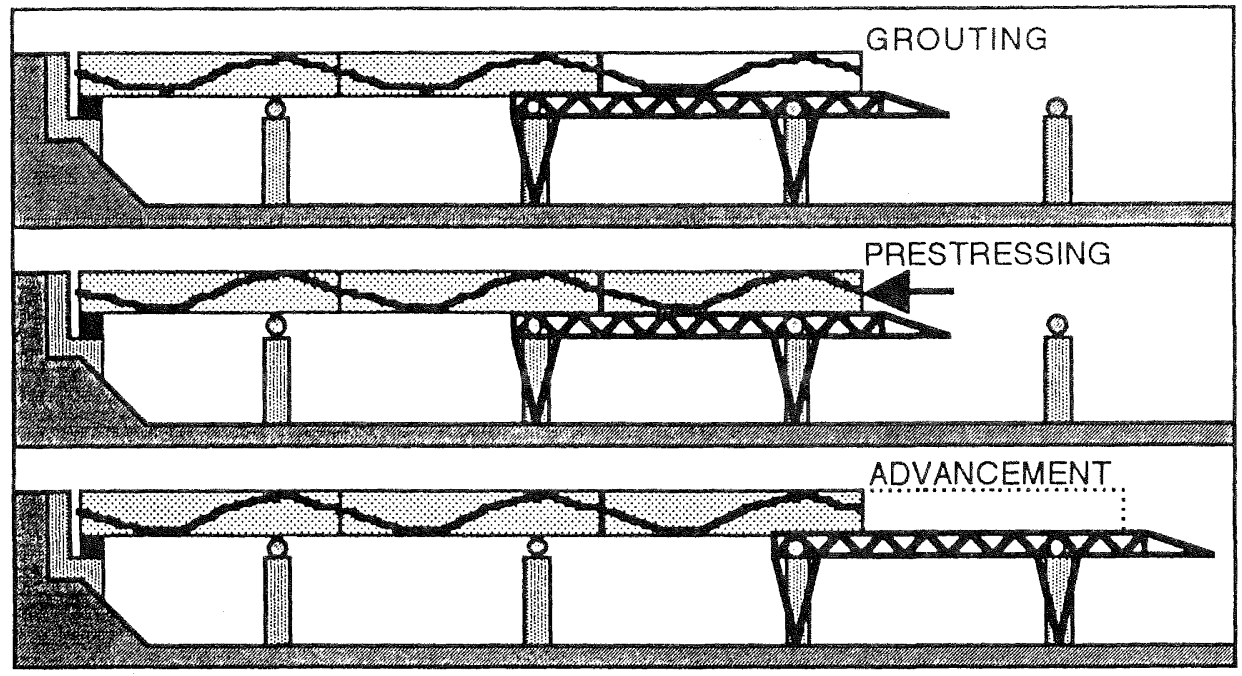

Fig.2 Progressive construction of continuous deck-beams

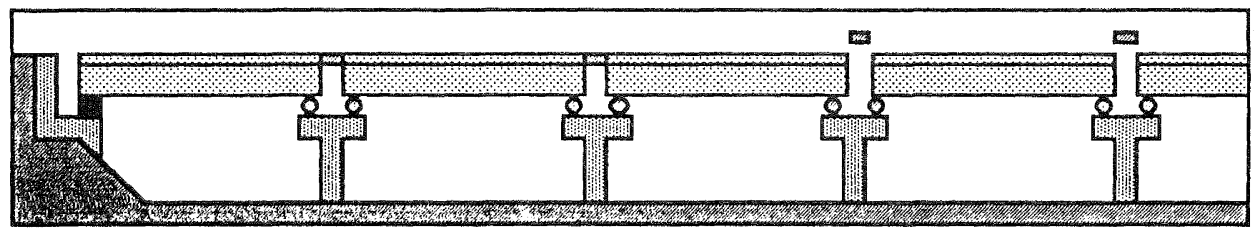

Fig.3 Prefabricated beams connected by deck elements

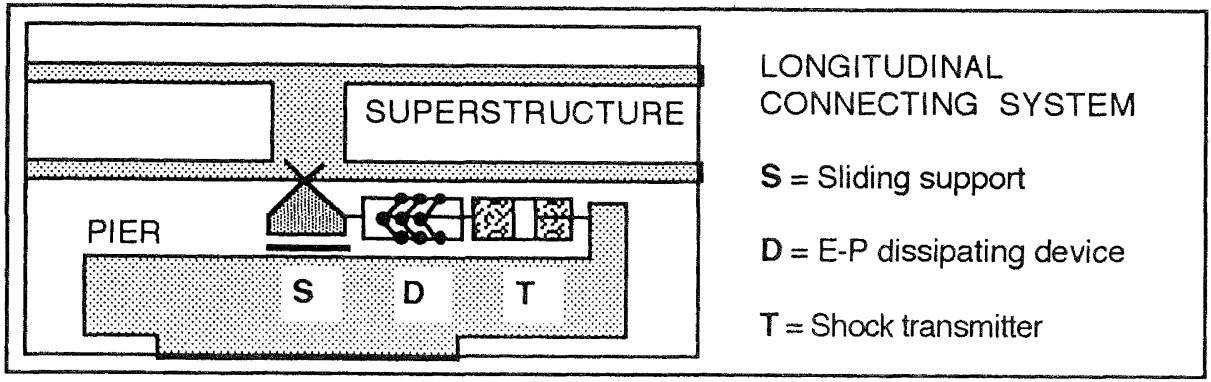

Fig.4 Devices of the longitudinal connecting system.

The design of the isolating system for continuous structures required preliminary investigations which were carried out in order to optimize the seismic behaviour of the structures when alternative isolating configurations were taken into account. Considerations are here developed and design criteria are analyzed, in order to identify optimum configurations in seismic design of continuous multi-span bridges. With this aim, comparisons are made between the performance of different structural configurations which were considered in the preliminary design.

\section{SEISMIC ISOLATING SYSTEMS}

The seismic isolation of the girder structures has been based on the elastic-plastic behaviour of bearing systems with which the deck structures are linked to the supporting structures (piers and abutments). In each bearing system, consisting of various mechanical devices, a traditional sliding support (element $\mathbf{S}$ shown in Fig.4) is connected with a hysteretic steel restrainer (element $\mathrm{D}$ ) which is characterized by elastic behaviour followed by plastic behaviour. In Fig.5a a typical hysteretic behaviour of the D-devices used for the construction of the bridges, having a nearly horizontal plastic threshold, is shown together with its 
respective bi-linear digital simulation (Fig.5b). The actual behaviour plotted in Fig.5a is derived from experimental investigations carried out on the actual restrainer devices, with which the real operating conditions were reproduced.

Since the sliding supports $\mathbf{S}$ transmit only vertical forces, the horizontal seismic forces are fully transmitted by the hysteretic steel restrainers $\mathbf{D}$. In such a way, the supporting system restricts the maximum horizontal seismic forces which can be transmitted between the deck structure and the piers, keeping these forces within the value of the yielding resistance point with which the devices have been designed and constructed. At the same time, during a major seismic attack, a great amount of mechanical energy is dissipated by means of the alternate hysteretic behaviour of the $\mathrm{D}$-device, so that the seismic displacements of the structure are suitably restrained.

The reduction of the transmitted forces makes the elastic design of the piers possible. The performance corresponding to an "Integral Seismic Protection" (ISP) can then be attained [8]. This performance can be reached even during a major expected earthquake, because the required bending resistance of the piers is reduced by the plastic behaviour of the horizontal restrainers, so that, beyond a certain limit, they do not depend on the seismic intensity. If this limit is exceeded, the only consequence is a greater excursion of the $\mathbf{D}$-device into its plastic range.

\section{ISOLATING SYSTEMS AND VOLUMETRIC VARIATIONS OF STRUCTURES}

Problems in previous design philosophy arise when volumetric changes of the deck structure are to be taken into account (thermal deformations, in addiction to creep, shrinkage and viscous effects of prestressed concrete structures) [9]. When, a continuous deck structure has to be connected to more than one pier, the isolating criterion which has been described causes some problems for the design of the structural configuration in the longitudinal direction. If the structure has to resist seismic attack, it is suitable that the resistance of all the piers are engaged. Therefore, during an earthquake, the deck structure has to be stiffly connected to the dissipating $\mathbf{D}$-devices, which ought to be placed on all the piers. Using normal connections, this performance is not compatible with the effects of the displacements caused by the volumetric changes of the deck structure. These could deform the D-devices alternatively at each thermal excursion, or permanently as a consequence of creep and shrinkage of the concrete elements.

\section{A-scheme: concentrated restrainers}

Three kinds of solution can be thought out in order to solve the problem. In a first solution (A-scheme shown in Fig.6), each section of the continuous structure is restrained by one only support, while all the other supports are of the sliding type in the longitudinal direction. In this case the same restraining distribution works during current operative conditions and during seismic attack. This simple configuration can be chosen if all the horizontal resistance of the deck structure can be suitably concentrated in a main supporting structure; for instance, when a joint-pier can be designed strong enough to resist all the seismic forces (Fig.6a). Chiefly, this is the case of a viaduct having only one continuous section which can be restrained directly to one of its abutments (Fig.6b). In this case, the abutment can be easily reinforced by means of tie-rods driven in the back soil.

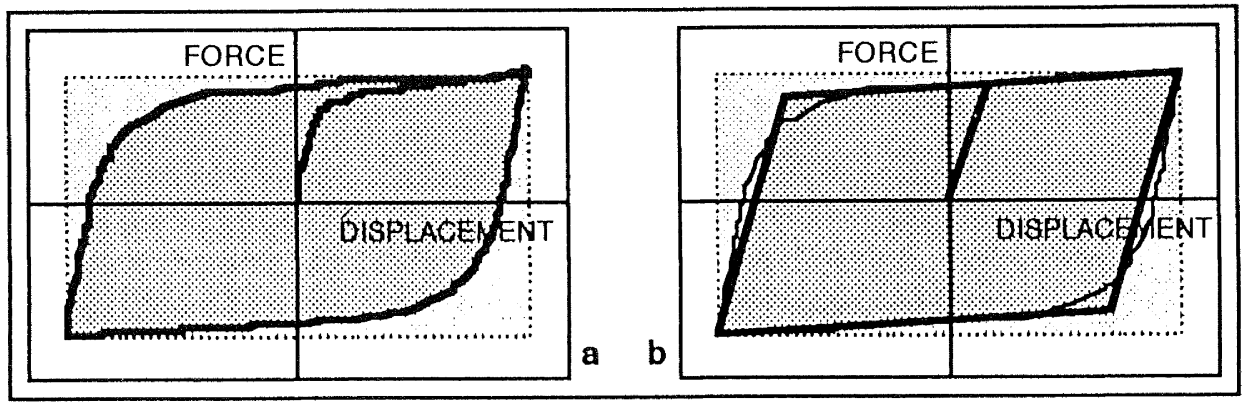

Fig.5 Experimental behaviour of an hysteretic restrainer (a) and its corresponding bi-linear simulation (b).

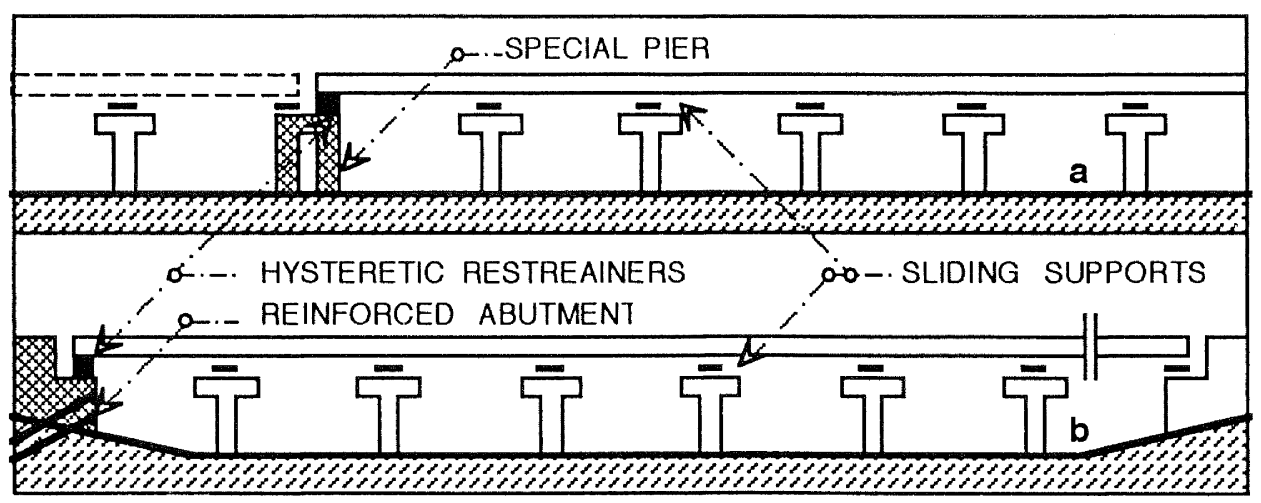

Fig.6 Typical configurations of A-scheme with only one seismic restrainer in the longitudinal direction. 
The main advantage of the A-scheme is that it allows the possibility to relieve the current piers of any required seismic resistance in the longitudinal direction. Obviously, at least two restrainers have to be active in the transverse direction. Generally, in all bearing positions, transverse restrainers can be inserted combining a longitudinal sliding $\mathbf{S}$-support together with an hysteretic D-device (Fig.5).

\section{B-scheme: distributed restrainers with neutral gaps}

A different solution (B-scheme) can be achieved by means of hysteretic devices stiffly connecting the bridge deck with only one pier, generally corresponding to the central pier of the section, while the side piers are provided with neutral gaps, in order to allow the thermal expansion of the deck [7,9]. In Fig.7, the whole longitudinal force-displacement behaviour of a typical $\mathbf{B}$-scheme is reproduced, with reference to a symmetrical 5-span structure.

The configuration of the $\mathbf{B}$-scheme can be selected in order to achieve simple solutions for multi-span structures. Moreover, construction problems can be solved when creep and shrinkage deformations of the beams are to be absorbed in pre-stressed concrete constructions. The point is that these deformations are not to be included in the seismic gaps of the restrainers. In any case, if this restraint distribution is assumed, it is advantageous that the yielding points of the restrainers and the horizontal resistance of the piers should be suitably differentiated because, due to the gaps, these structural elements are differently engaged during a seismic attack. Thus this scheme has to be disregarded, because the following $\mathrm{C}$-scheme has been considered more effective.

\section{C-scheme: distributed restrainers with shock-transmitters}

Finally, the third configuration ( $\mathrm{C}$-scheme) can be used in order to leave all volumetric deformations free to occur (thermal, creep and shrinkage effects). In the longitudinal direction, the deck-structure is connected to the head of the piers by means of a compound connecting system in which three different behaviour patterns are provided by three different devices, as is shown in the previous Fig.4, where the S-device is a traditional sliding support and the $\mathbf{D}$-device is an hysteretic elastic-plastic restrainer. In addition, the T-device is an viscous mechanism which behaves in a highly viscous way: no force is transmitted if quasi-static deformations, as are the thermal ones, are imposed. On the contrary, it jams when dynamic forces, such as those produced by a seismic attack, are imposed, so that it behaves as a "shock-transmitter".

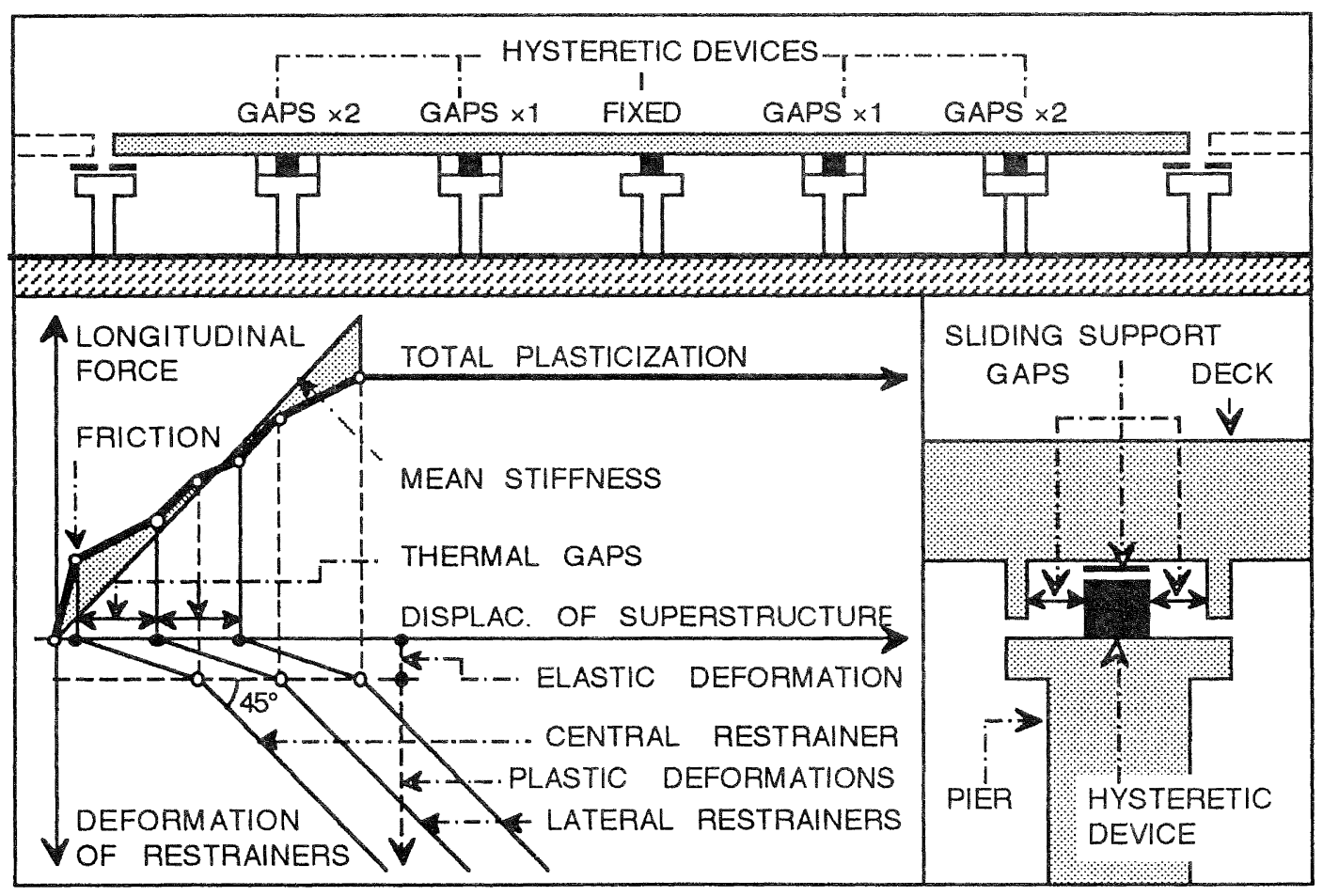

Fig.7 Longitudinal behaviour of B-scheme with reference to a 5 -span continuous bridge section. 
THE MORTAIOLO BRIDGE

General lay-out

The Mortaiolo Bridge is one of the major structures designed for the Livorno-Civitavecchia highway. It is a two-line bridge nearly $10 \mathrm{~km}$ long. It has been designed in order to cross the large plain composed of deep soft clay stratifications, lying near Livorno. Its general configuration consists of various multi-span continuous sections of prestressed concrete deck structure, built by a progressive procedure. The structural configuration of the standard section is made up of 10 continuous spans, having a total length of $432 \mathrm{~m}$ ( 8 normal spans of $45 \mathrm{~m}$, plus two boundary spans of $36 \mathrm{~m}$ ). Each continuous section is supported by reinforced concrete piers of almost uniform height in each continuous section. The heights of the piers range from 5-6 m to $11-12 \mathrm{~m}$. All the structures are supported by deep foundations, by means of piles driven into the soft clay soil. At present, (1991) the structures are being built.

The general lay-out of the main elements of one of the two-line viaducts is shown in Fig.8. The unusual slenderness of the deck structure must be pointed out.

The seismic isolation system of the Mortaiolo Bridge has been based on a $\mathbf{C}$-scheme, in which elastic-plastic devices behave both in longitudinal and transversal directions. The compound apparatus has been provided in all the piers of each continuous section, except in the main position at the centre of the section, where the supports are not of the sliding type and therefore there are no shock transmitters. Moreover, the supports on the joint-piers are of the sliding type only, due to geometrical necessity.

\section{Design procedure}

The seismic design of the bridge has been carried out developing numerical analyses by means of direct integration of dynamic equations based on step-by-step procedures, and using the DRAIN-2D digital time-history program. Two careful bidimensional structural models have been arranged in order to calculate the seismic responses in the longitudinal and transverse directions. Four artificial earthquakes have been derived from the S2-GNDT design spectrum [3], with a $0.25 \mathrm{~g}$ peak ground acceleration and using the SIMQKE program. The mean and the maximum values of the calculated responses have been considered.

\section{Seismic performances}

The insertion of the isolating system described above has given rise to very satisfactory seismic responses. The attainment of the above mentioned ISP condition, due to the reduction of the bending moments in the piers, can be considered as the main result. As an example, in Fig.9, with reference to a typical 10spans section of the Mortaiolo Bridge, the demands of bending moments at the bottom of the piers in the non-isolated structure are compared to those of the corresponding isolated structure. This reduction has made it possible to design the yielding resistance of the piers higher than those produced by the major design earthquake. Furthermore, the configuration of the bridge, in which the predominant masses are in the deck structures, makes this calculation reliable: since the maximum bending moments in the columns derive mainly from the inertia of the deck masses transmitted by the plastic restrainers, their resistance could be directly designed on the basis of results of experimental tests carried out on the actual samples of the bearing apparatus.

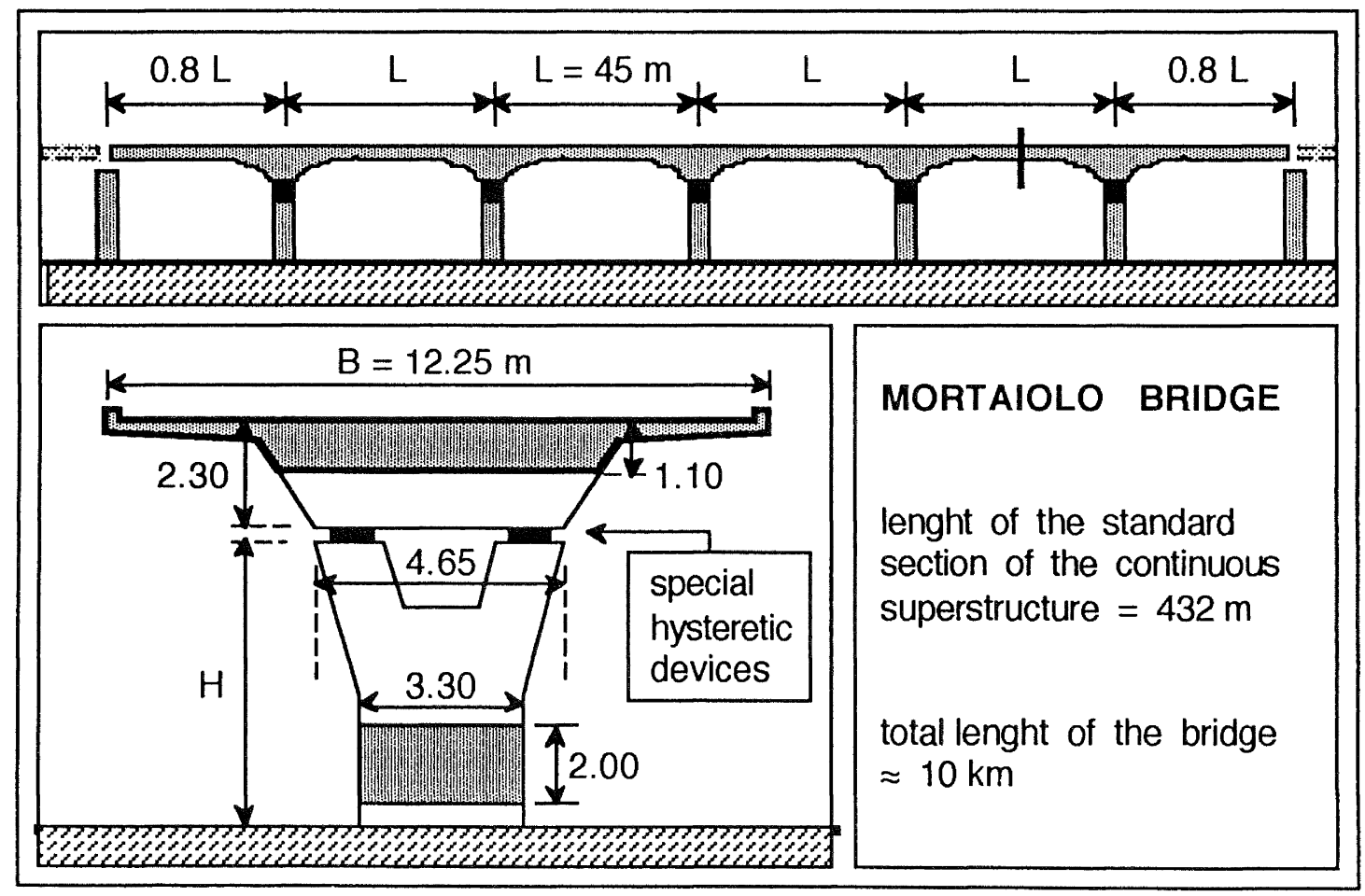

Fig.8 General lay-out of the Mortaiolo Bridge. 


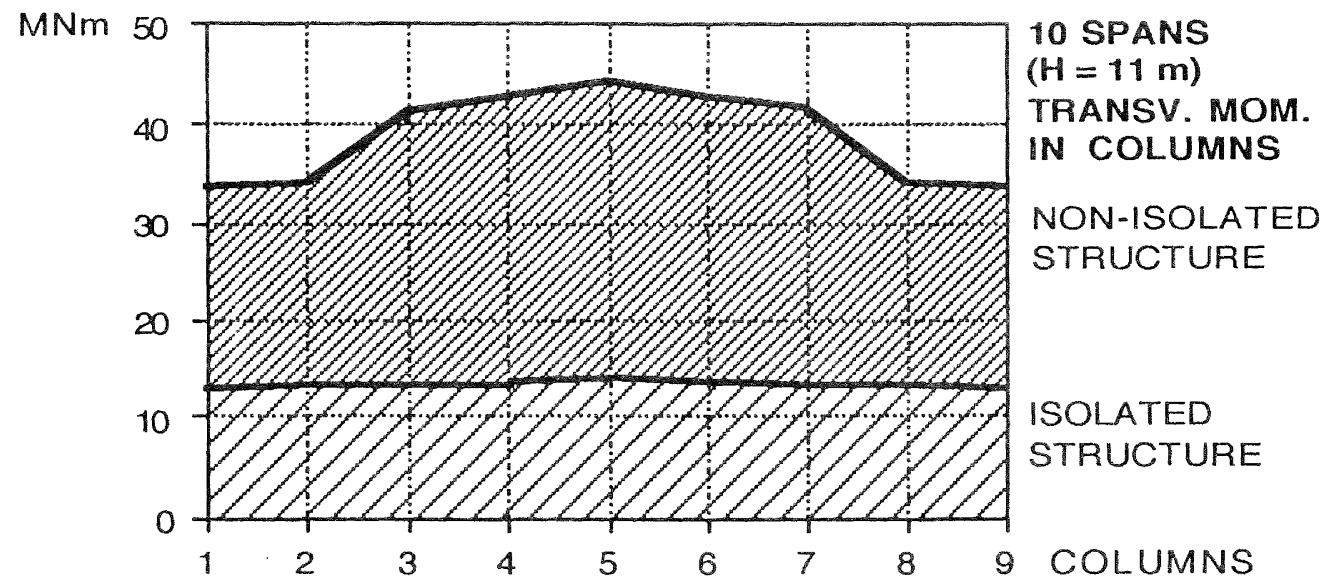

Fig.9 Bending moments in the columns of the isolated and non-isolated structure (10-spans section; piers: $\mathrm{H}=11 \mathrm{~m}$; maximum design earthquake).

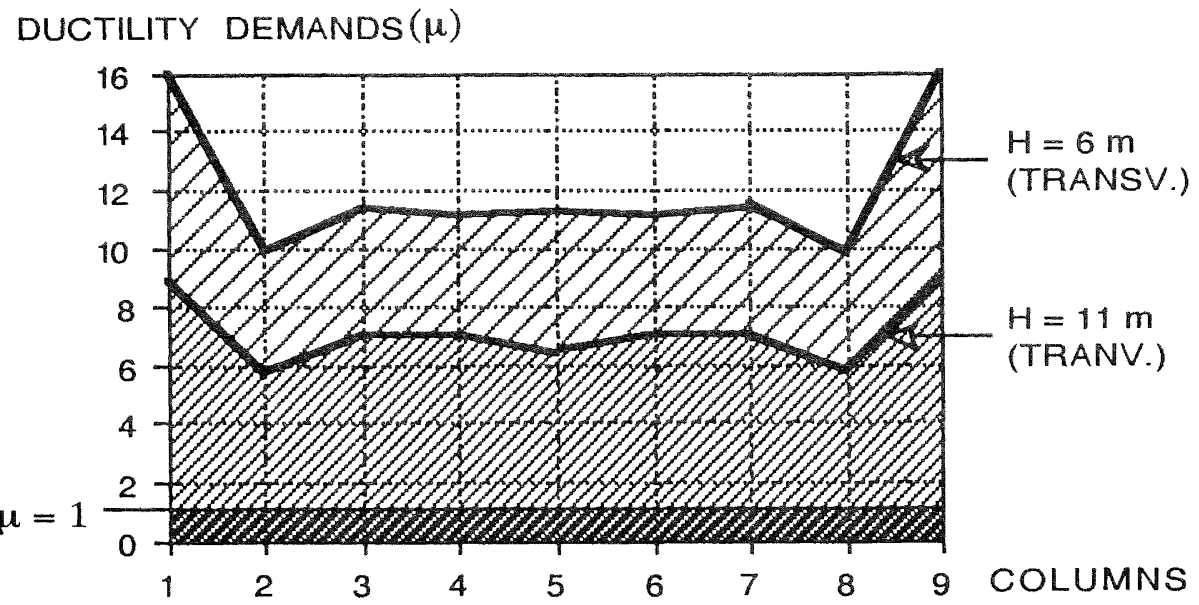

Fig.10 Demands of lateral ductility in typical 10-span continuous sections having constant pier heights $(\mathrm{H}=11 \mathrm{~m}$ and $\mathrm{H}=6 \mathrm{~m})$

Again considering a typical 10-span section, Fig. 10 refers to structures in which stiff connections between the deck and the piers have been considered, designed with a resistant moment equal to those actually designed for the isolated structure, with which the ISP performance has been attained. Ductility demands in plastic hinges formed at the bottom of the columns are plotted. The graph emphasizes the better behaviour of the isolated structure, which had been designed to remain in the elastic range $(\mu<1)$.

\section{Economical estimations}

General estimating calculations have been developed in order to evaluate the economical advantages which can be attained with the use of seismic isolation in such a structure. For this purpose, the expected reduction in the repair costs owing to the improved protection achieved with seismic isolation have been considered. Supposing a suitable incidence of the indirect costs ( $50 \%$ of the direct repair costs), the calculations have been carried out on the basis of the criteria illustrated in [10]. An annual discount rate of $5 \%$ and an annual depreciation of $3 \%$ for the structure have been considered. In this way, the percentage of $9.5 \%$ of the building costs of the bridge has been estimated as the economical limit of the incremental cost of the seismic isolating apparatus. As shown in the previous tables, the real cost of the isolating devices has been equal to only $4.8 \%$ of the bridge cost.

\section{Mortaiolo Bridge Isolating devices}

Two equivalent isolating devices, manufactured by Italian firms, have been utilized in the bridge $[5,6]$. Though they are based on different mechanical systems, they respond in the same elastic-plastic way. In both the devices the dissipating behaviour is based on the hysteretic flexural deformations of steel elements. 


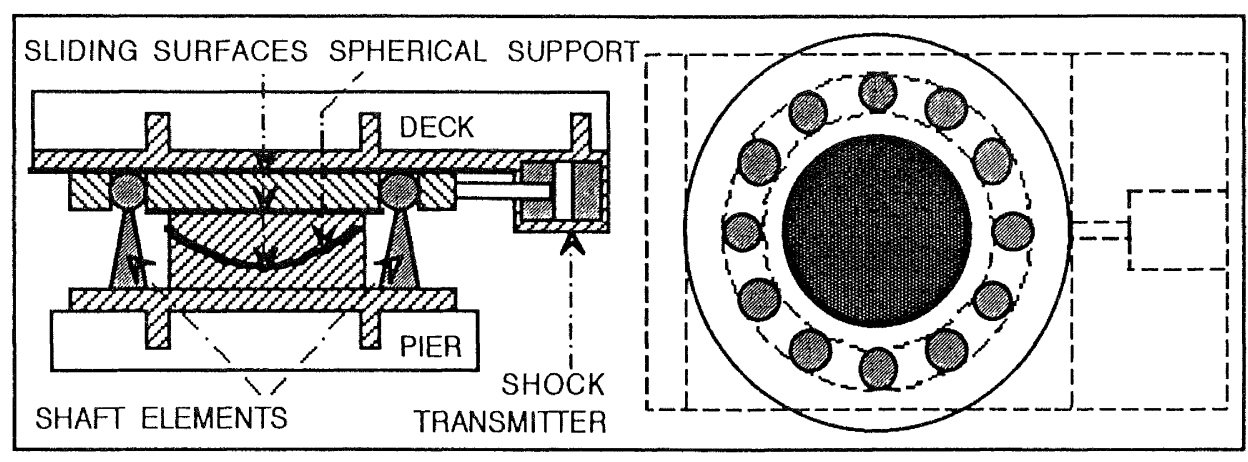

Fig.11 Scheme of the shaft-type elastic-plastic device.

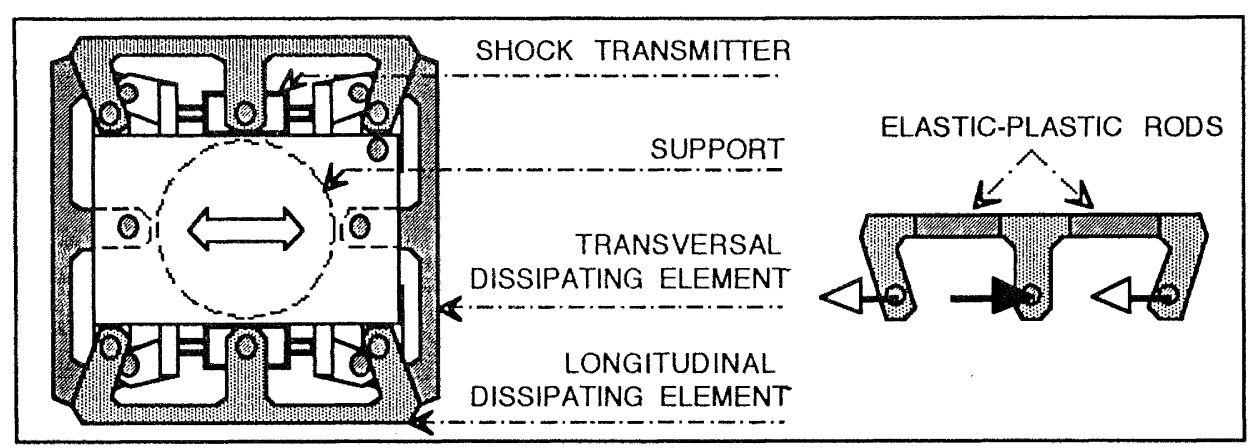

Fig.12 Scheme of the frame-type device.

In Fig.11 the shaft-type device is shown. The particular configuration of the shaft-element produces lateral flexural deformations in which all the shaft works in an uniform plastic way, so that large and equal plastic behaviour can be attained in all horizontal directions. Therefore, its plastic domain is represented by a circular pattern.

In Fig. 12 the frame-type device is reproduced. Each frame is an uni-directional element which works with plastic deformations of the transverse rod. Its configuration assures a symmetrical behaviour in both forward and backward directions. In order to obtain a multi-directional horizontal behaviour, two pairs of frame elements are arranged in a right-angled configuration. The plastic domain of the compound apparatus is then represented by a square pattern.

Longitudinal deformations due to volumetric changes of the concrete deck had to be allowed for. Furthermore, significant rotations and additional longitudinal deformations had to be foreseen during the construction stages as a consequence of the large flexural deformability of the deck structure. Two sliding surfaces were then designed in each bearing apparatus: the first one absorbs these deformations, while the other works when the seismic restrainers are engaged.

\section{Acceptance tests}

To check the performance of current bearing devices, particular acceptance tests have been carried out in order to control both the elastic and plastic behaviour of the seismic mechanisms. Tests have been performed both on the single dissipating elements and on the whole apparatus, reproducing the behaviour foreseen in the seismic design of the bridge. The testing procedures were established as follows [9]:

1) Elastic tests, consisting on 10 cycles of alternative deformations to be imposed in the range $\pm 0.8 \mathrm{Sy}$, where Sy is the elastic limit displacement at the nominal yielding point.

2) Elastic-plastic tests, consisting of 10 cycles of alternative deformations to be imposed in the maximum range $\pm S \max$, where Smax is the displacement calculated for the maximum expected earthquake.

It has been required that the force-displacement curves plotted in the tests shall be within the range of the theoretical values with fixed tolerances and the dissipating behaviour will be guaranteed by the ratio of the hysteretic cycles to the area of the rectangle defined by the values of the maximum force and maximum imposed displacement (Fig.5). In Fig. 13 the practical criterion with which the characteristic parameters are derived by the tests is illustrated. 


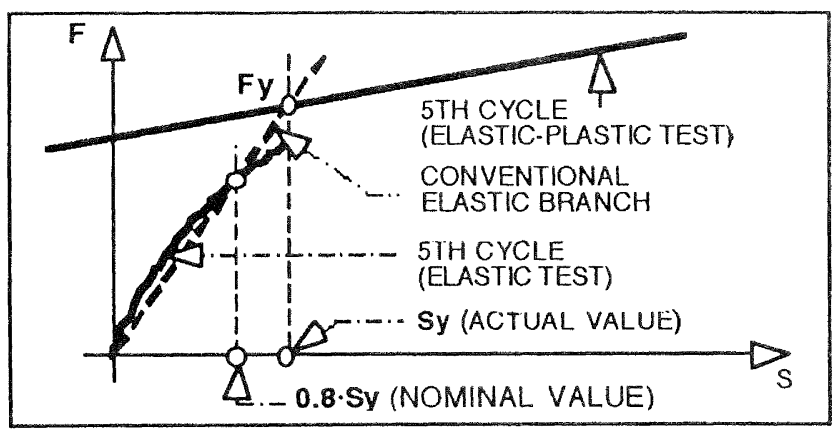

Fig.13 Practical criterion for the valuation of the characteristic parameters from experimental tests

\section{FURTHER APPLICATIONS OF THE COMPOUND DEVICES}

The use of the complete compound devices, shown in Fig.4, are suitable for the design of other particular seismic configurations. For instance, if in the central part of a continuous deck section tall and slender columns are present, a structural configuration can be suitably designed stiffly connecting the head of these columns to the deck structure, in order to reduce their seismic free oscillation during a major seismic attack; thereby, the inertia of the equivalent masses of the piers are also transmitted to the dissipating device.

An example of this configuration is represented in Fig.14, where an $\mathbf{A}$-scheme, similar to the one shown in Fig.6b, has been considered. Furthermore, in the case of a single continuous section, the compound apparatus (with a T-element) can be applied to the right abutment, so that both the abutment resistances are engaged in the longitudinal direction. This configuration turned out as a suitable expedient when some existing bridges were retrofitted.

\section{GENERAL COMMENTS ABOUT THE ISOLATING STRATEGIES}

Generally, two main strategies can be considered in order to provide a structure with an isolating system which guarantees its seismic protection $[6,8,10]$. The first one (the $\mathbf{T}$-strategy) is based on the shift of the natural period of the structure in the field of lower seismic responses. This goal is attained by inserting elastic low-stiffness connections between some structural elements or between the whole of the building and its foundation (base isolation). The second one (the $\mathbf{Y}$-strategy) is based on the dissipation of the mechanical energy, which the earthquake transmits to the resistant structure, by means of hysteretic elastic-plastic devices; the higher intensities of the seismic forces are then reduced, thanks to the effect of the plastic threshold, while a significant amount of mechanical energy is dissipated by cyclic hysteretic deformations.

From a practical point of view, in the field of bridge construction, the authors think that generally the $\mathbf{Y}$-strategy is to be preferred. On this subject, it must be pointed out that the T-strategy is highly sensitive to the real configuration of the local response spectra $[6,10]$. Therefore a reliable knowledge of the response spectra pattern of the actual earthquakes expected at the site is required. The frequency band in which the energy input is mainly transmitted must be well recognized with reference to the local geological conditions, in order to avoid the natural period of the structure being artificially shifted to this band.

Unfortunately, this kind of knowledge can be seldom achieved. In the case of the Mortaiolo Bridge, the presence of deep stratifications of very soft soils left no doubt in selecting the suitable strategy. Furthermore, the results which can be attained with the $\mathbf{Y}$-strategy are more uniform and do not depend so much on the primitive natural period of the structure and the non-isolated structural configuration $[6,10]$.

On the basis of these considerations, the $\mathbf{Y}$-strategy has been considered the better choice for the Mortaiolo Bridge, taking also into account that the various continuous sections can have different natural periods, due to the different values of the mean height of the piers. Therefore, the choice of an elastic-plastic isolating system made the utilization of the same devices in all of the piers possible. Then, the reinforcement in each pier was calculated in accordance with the flexural yielding resistance required by the seismic input.

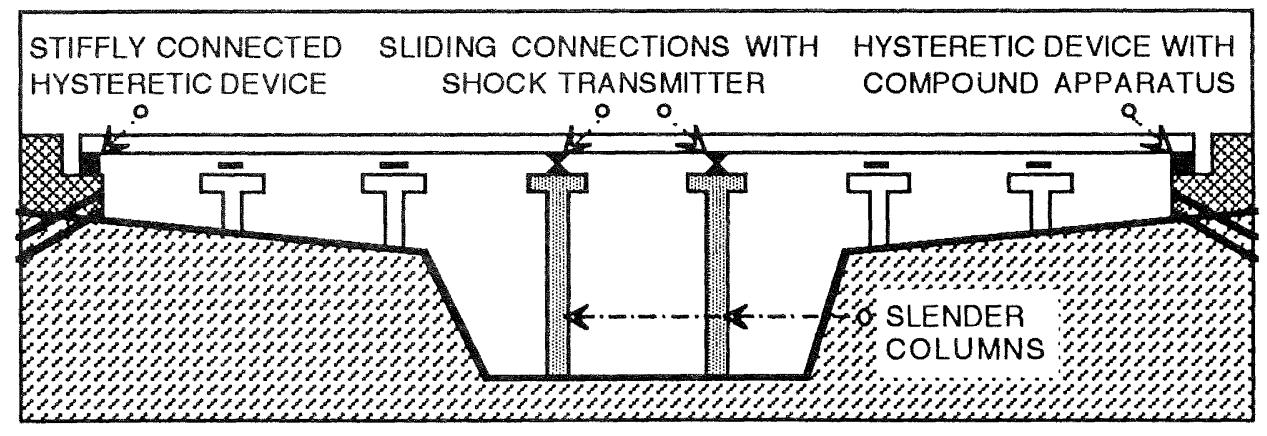

Fig.14 Longitudinal restrainers of a continuous deck bridge in presence of slender columns. 


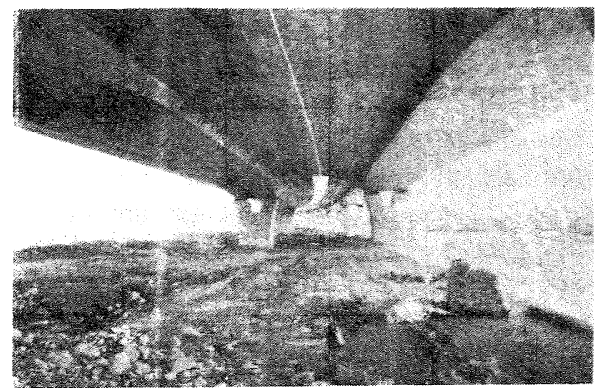

Fig.15 General view of a typical span of the Mortaiolo Bridge.

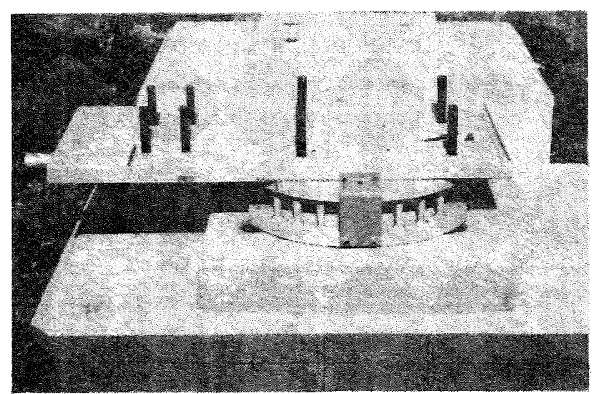

Fig.17 View of a complete device with shaft elements.

\section{ACKNOWLEDGEMENTS}

The design of all the works of the motorway Livorno-Cecina, including the Mortaiolo an Morra Bridges, was carried out by the Italian Firm Sotecni S.p.A. (Società Autostrada Tirrenica) from Roma, both of the Iri-Itaslstat Group.

The building of the Mortaiolo Bridge has been allocated to A.T.I. (Associazione Temporanea di Imprese) formed by the Italian Firms Italstrade, Gambogi, Coestra and Sticea, while the isolating devices were constructed by the Italian companies [6,7]: Fip-Industriale from Padova, Silfa from Palermo and Alga from Milano.

The design of the seismic protection system of the Mortaiolo Bridge was assigned to the authors of this paper.

\section{REFERENCES}

[1] Chiarugi A., Galanol., Spinelli P.: "II progetto di apparecchi dissipatori ad isteresi metallica nella protezione sismica dei ponti a travata continua", International Meeting on Base Isolation and Passive Energy Dissipation - Università di Perugia - Assisi (Italy), 8-9 Giugno 1989.

[2] De Nunno R., Parducci A.: "Una breve rassegna dei moderni sistemi di isolamento sismico delle costruzioni", - Congresso CTE - Venezia (Italy) 1988.

[3] GNDT-CNR (Grupp Nazionale per la Difesa dai Terremoti - Consiglio Nazionale delle Ricerche): Norme Tecniche per le Costruzioni nelle Zone Sismiche - Roma (Italy), Dic. 1984.

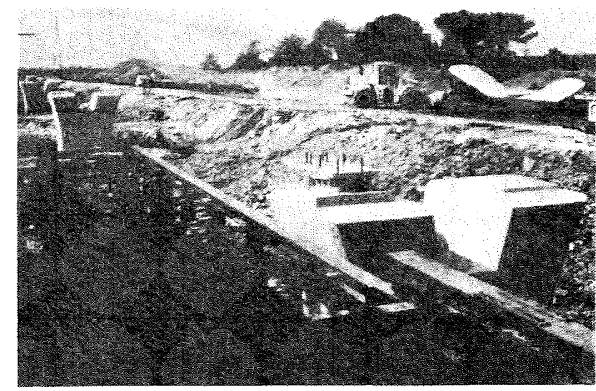

Fig.16 The Mortaiolo Bridge during the building procedure.

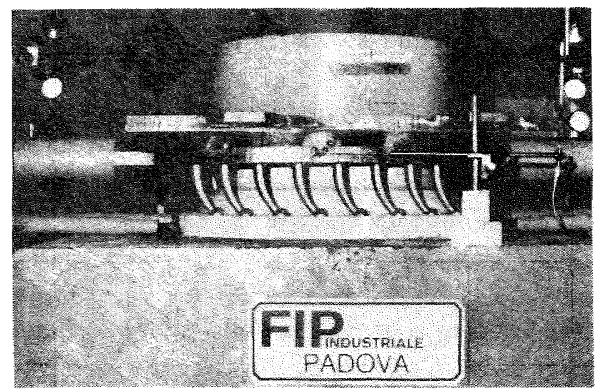

Fig.18 A complete bearing-isolating device during an experimental test.

[4] Marioni A.: "Apparecchi di appoggio per ponti e strutture", - International Meeting on Base Isolation and Passive Energy Dissipation - Università di Perugio Assisi (Italy), 8-9 Giugno 1989.

[5] Medeot R.: "Lo sviluppo dei dispositivi di ritegno antisismico per impalcati da ponte", - International Meeting on Base Isolation and Passive Energy Dissipation - Università di Perugia - Assisi (Italy), 8-9 Giugno 1989.

[6] Mezzi M., Parducci A.: "Optimum behaviour for seismically isolated buildings", - 9th EAEE Conference -Moscow (URSS), Sept. 1990.

[7] Parducci A., Medeot R.: "Special dissipating devices for reducing the seismic response of structure", Pacific Conference on Earthquake Engineering - New Zealand Society for Earthquake Engineering - Wairakei (New Zealand), Aug.1987.

[8] Parducci A.: "Isolamento sismico e sistemi dissipativi Relazione generale", International Meeting on Base Isolation and Passive Energy Dissipation - Università di Perugio - Assisi (Italy), 8-9 Giugno 1989.

[9] Parducci A.: "Considerazioni sui criteri di progetto delle strutture da ponte con impalcato sismicamente isolato", - International Meeting on Base Isolation and Passive Energy Dissipation - Università di Perugia Assisi (Italy), 8-9 Giugno 1989.

[10] Parducci A.: "Design strategies and economical benefits in seismic isolation", - Pacific Conference on Earthquake Engineering - Auckland (New Zealand) 2023 Nov. 1991. 